(Aus dem Hygienischen Institut der Universität Basel

[Vorstand: Prof. Dr. R. Doerr].)

\title{
Die Blutgifte der Pneumokokken.
}

\author{
Von \\ Dr. Alfred Schnabel.
}

Unter den Blutgiften im allgemeinen nehmen in der Literatur die von den Bakterien gebildeten eine Sonderstellung ein. Während man die chemischen Blutgifte je nach ihrem Angriffspunkt und ihrer Wirkungsart in verschiedene Gruppen unterscheidet, wie z. B. blutlösende, methämoglobinbildende usw., deckt sich bei den bakteriellen die Bezeichnung „Blutgift" mit ihrer Klassifizierung als blutlösende Gifte. Der hierfür geprägte Ausdruck „Hämotoxin" bedeutet ein blutlösendes Bakterienprodukt mit Antigennatur. Daß diese Definition der bakteriellen Blutgifte zumindest in bezug auf die Pneumokokken einseitig ist, möge aus folgenden Darlegungen ersehen werden.

Die verschiedenen Typen der Streptokokkenfamilie unterscheiden sich bekanntlich außer durch andere morphologische und kulturelle Merkmale auch durch ihre Eigenschaft, auf der Blutplatte um die Kolonien bald einen hämolytischen, bald einen grünen oder auch gar keinen Hof zu bilden. Schon 1896 haben Gilbert und Fournier die gelbe bis schokoladebraune Verfärbung im Blutnährboden als charakteristisch für das Wachstum der Pneumokokken hervorgehoben. Später machte Weichselba u m auf die grüne Farbe der Klappenauflagerungen bei durch Pneumokokken hervorgerufenen Endokarditiden aufmerksam (s: auch Ry mowicz). Schottmüller benützte dann dieses Verhalten gegen Blutfarbstoff zur Differenzierung der verschiedenen Streptokokkentypen voneinander. Dieser Autor beobachtete diese Erscheinung auch in einer anderen Versuchsanordnung, und zwar durch Zusatz von Blut zur reifen Bouillonkultur verschiedener Kokken und konnte feststellen, daß die Eigenschaft der Grünfärbung des rotgefärbten Nährbodens dem Str. mucosus, Str.viridans und dem Preumokokkus zukommt. Dagegen vermißte Schottmüller die blutlösende Wirkung beim Pneumokokkus und Streptococcus mucosus.

Rieke hat dann auf Tjadens Anregung die Frage nach dem Wesen der Verfärbung des Blutes zu lösen gesucht; und zwar bei der durch Streptokokken im engeren Sinne bewirkten rotbraunen Verfär- 
bung desselben nach erfolgter Hämolyse. Er fand spektroskopisch eine der Methämoglobinbildung entsprechende. Veränderung unter dem Einfluß lebender Streptokokken im Verlaufe von 12-24 Stunden. Diesen Befund bestätigte Boxer. Auch Grüter, der sich eingehend mit der Methämoglobinbildung durch Streptokokken beschäftigte und diese Erscheinung von der Hämolyse abtrennte, sah die charakteristische spektroskopische Veränderung bei allen Streptokokkentypen.

Diese Beobachtung der Methämoglobinbildung bei allen Streptokokken hat allerdings nichts an der Tatsache geändert, daß in der Praxis nur die Verfärbung durch Pneumokokken, Str. mucosus und Str. viridans in Betracht kommt. Es bestehen hier neben wahrscheinlichen qualitativen Unterschieden in der Art der Einwirkung auf den Blutfarbstoff im Sinne der spektroskopisch wahrnehmbaren charakteristischen Veränderungen auch weitgehende Unterschiede in quantitativer Beziehung. Vor allem ist zu bedenken, daß Methämoglobinbildung auf sehr verschiedene Weise zustande kommen kann. So ist unter Umständen eine ganz unbeimpfte Bouillon - in der Regel allerdings erst bei längerer Einwirkungsdauer - imstande, den Blutfarbstoff so zu verändern, daß er im Spektroskop die für das Methämoglobin charakteristischen Absorptionsstreifen zeigt. Gerade diese lange Einwirkungsdauer und das nur wenig ausgesprochene Vermögen zur Um. wandlung des Blutfarbstoffes sind es, die in der bakteriologischen Praxis das Methämoglobinbildungsvermögen (Grünfärbung des Nährbodens) anderer Streptokokken neben dem der Pneumokokken und des Str. mucosus und Str. viridans zu vernachlässigen gestatten. Denn während die Umwandlung durch die ,grünfärbenden" Streptokokken, also die Pneu mokokken, Str. mucosus und Str. viridans, in wenigen Minuten bis 1-2 Stunden in der Regel erfolgt, vermögen die anderen Typen dieses Phänomen erst nach vielen Stunden - und. auch dann nicht immer - hervorzurufen. Von gewissen Ausnahmen soll jedoch abgesehen werden.

So konnten von mir in letzter Zeit aus zwei verschiedenen Sputen zwei Streptokokkenstämme gezüchtet werden, die weiße Mäuse in $10 \mathrm{bzw}$. 12 Stunden töteten und die in der ersten Kultur die Blutagarplatte diffus graubraun färbten. Eine durch einen Tropfen Blut rotgefärbte Bovillonkultur färbte sich in einer halben Stunde bei $37^{\circ} \mathrm{C}$ graubraunrot und im Spektroskop waren die für das Methämoglobin charakteristischen Streifen zu sehen. Schon die zweite Kultur auf Blutagar jedoch ergab, daß es sich um einen Str. haemolyticus handelt: die kleinen, trockenen Kolonien waren von einem breiten, hcllen hämolytischen Hof umgeben. Auch ein Gegenstück dazu konnte beobachtet werden. Ein aus einem Pleuraexsudat gezüchteter Streptokokkus wuchs in der ersten Kultur auf der Blutagarplatte äußerst zart unter Bildung schwach hämolytischer Höfe. Nach mehrmaliger Überzüchtung erwies er sich als ein Streptococous viridans.

In diesem Zusammenhang sei auch auf die von Kuczynski und Wolff vor kurzem mitgeteilte Beobachtung verwiesen. Diesen Autoren gelang es, aus rein bämolytischen Streptokokken im Tierversuch Viridanskeime zu züchten, und zwar besonders häufig aus der Lunge der einige Stunden nach der intraperitonealen Injektion getöteten Mäuse. Zur Erklärung dieses Befundes wird die Beobachtung herangezogen, daß man auch zuweilen beim Str. haemolyticus vor dem Stadium der vollständigen Hämolyse ein solches sehen kann, das durch deutliche grüne Verfärbung des Nährbodens gekennzeichnet ist, besonders gut bei Verwendung von Ziegenblutagar in dünner Schicht, noch besser aber bei Züchtung auf Levinthalschem Agar, der mit den zentrifugierten Blutkörperchen des Citratblutes hergestellt wurde. Verfasser denken bei diesem Utbergang des Str. haemolyticus 
in Viridanskokken an eine Fermenthemmung bei Keimen, die, bereits geschädigt, gerade vor der Abtötung durch den Wirtsorganismus isoliert werden, unter Beibehaltung der verkümmerten Zelleistungen in Form gehemmter Hämolyse (s, auch Jacobsthal).

In neutrer Zeit hat die Frage der Methämoglobinbildung durch Pneumokokken eine eingehende Bearbeitung durch amerikanische Autoren erfahren (Butterfield und Peabody, Peabody, Cole R.). Die Resultate der einzelnen Autoren stimmen nicht überein. Wohl fanden alle die Entstehung von Methämoglobin als Ursache der eigenartigen Verfärbung bluthaltiger Nährböden. Doch bestehen wesentliche Differenzen in bezug auf die Auffassung des wirksamen Agens. Während Butterfield und Peabody ein filtrierbares Produkt annehmen, schließt Cole auf Grund seiner Versuche, daß diese Umwandlung des Hämoglobins eine Funktion der lebenden Bakterienzelle ist.

Neben den erwähnten widersprechenden Befunden verschiedener Autoren steht also als gemeinsame Tatsache fest, daß die Pneumokokken die Eigenschaft haben, den Blutfarbstoff in Methämoglobin umzuwandeln. Daß diese Eigenschaft nicht ohne Belang sein kann fürr den Organismus, in dem die Pneumokokken zur Anreicherung gelangen, ist zumindest nicht zu verneinen. Eine selbstverständliche Annahme einer Giftwirkung erscheint jedoch nicht zulässig, da sich die Ergebnisse von Kultur- und -Reagensglasversuchen nicht immer auf die Vorgänge im Organismus übertragen lassen. Diesen zwei Gesichtspunkten und zwar der Frage, ob das wirksame Agens nur an die lebende Zelle gebunden oder ein Sekretionsprodukt ist und ferner der Frage nach der pathogenetischen Bedeutung desselben entspringen die hier mitgeteilten Versuche.

Auf das hämolytische Vermögen der Pneumokokken, insbesondere auf die Beziehungen zwischen der $p_{\mathbf{r}}$-Zahl des Nährmediums und der Hämolyse durch Pneumokokken soll in einer späteren Mitteilung näher eingegangen werden. Diese Eigenschaft soll hier nur insofern berührt werden, als sie mit dem Vermögen der Pneumokokken, den Blutfarb. stoff zu beeinflussen, im Zusammenhang steht.

Zur Untersuchung gelangten zehn Pneumokokkenstämme und vier Stämme von Str. mucosus. Von den Pneumokokkenstämmen entstammten vier pleuritischen Exsudaten, drei Otitis media-Erkrankungen, zwei wurden aus Lungenauswürfen und einer aus einem perikarditischen Exsudat gezüchtet. Die Str. mucosus-Stämme konnten bei 3 Fällen von Otitis media acuta und einem Fall von Hirnabsceß (im Anschluß an eine Mittelohrentzündung) gezüchtet werden. Daß außer den Pneumokokken auch die Mucosusstreptokokken zur Untersuchung herangezogen wurden, geschah mit Rücksicht auf die innigen verwandtschaftlichen Beziehungen beider Typen. Bis auf Unterschiede in bezug auf die Tierpathogenität und das Aussehen der Kolonien bestehen bekanntlich 
keine wesentlichen, mit den üblichen Laboratoriumshilfsmitteln wahrnehmbaren Differenzen. Wichtige biologische Untersoheidungsmerkmale, das Verhalten gegen Galle und Optochin lassen hier im Stiche. Gewisse Unterschiede im Verhalten gegen verschiedene Zuckerarten, die auch zwischen verschiedenen Pneumokokkenstämmen nicht selten sind, kommen praktisch kaum in Frage. Und auch das für den Str. mucosus charakteristische Aussehen der Kolonien, die zumeist eine schleimige Beschaffenheit aufweisen, ist nicht immer - zumindest nicht auf allen Nährböden - wahrzunehmen. Sicherlich bestehen Unterschiede in immunologischer Beziehung. Es kann daher nicht wundernehmen, da $B$ - was schon hier vorweggenommen werden möge - die bei Reagensglasversuchen erhaltenen Resultate für Pneumokokken und Mucosuskeime vollkommen identisch sind. Es werden daher nur die mit den Pneumokokken ausgeführten Versuche näher beschrieben. Zwischen den verschiedenen Stämmen untereinander ergaben sich in bezug auf das Methämoglobinbildungsvermögen nur graduelle und keine prinzipiellen Unterschiede.

Als Kulturmedium diente eine Blutbouillon, die durch Zusatz von $1 / 2$ Tropfen Kaninchen- oder Meerschweinchenblut im defibrinierten oder undefibrinierten Zustande pro $1 \mathrm{ccm}$ Fleischwasser- bzw. Fleischextraktbouillon hergestellt wurde. Der Zusatz von nicht defibriniertem Blute erwies sich aus Sterilitätsgründen als praktischer und erfolgte in der Weise, daß das mit einer Glas- oder Rekordspritze durch Herzpunktion gewonnene Blut direkt den Bouillonröhrchen oder -kölbchen zugesetzt wurde. Die nachher eintretende Blutgerinnung in der Bouillon fiel als Nachteil kaum in die Wagschale. Von flüssigen Nährböden kamen noch Serum- und Traubenzuckerbouillon, von festen Löfflerserum und Blutagar in Platten zur Verwendung.

Die spektroskopische Untersuchung wurde mittels des KirchhoffBunsenschen Spektroskops und des Bürkerschen Vergleichsspektroskops ausgeführt. Das Kirchhoff-Bunsensche Spektroskop, das eine Skala trägt, wurde vorher mittels der Frauenhofersehen Linien des Sonnenspektrums geeicht und die den einzelnen Skalenteilen entsprechenden Wellenlängen im Ordinatensystem als Kurve aufgezeichnet.

Sämtliche untersuchten Pneumokokken- und Mucosusstämme zeigten die charakteristische Umwandlung des Blutfarbstoffes also einen grünlichen Hof um die Kolonien auf der Blutagarplatte, Verfärbung der durch Zusatz von Blutfarbstoff in Form aufgelöster oder ganzer Erythrocyten vorher rot gefärbten Bouillonkultur usw. Die Versuche mit Bouillonkulturen wurden in der Regel so ausgeführt, daß die in der Blutbouillon nach 24 Stunden gewachsene Kultur von dem, einen Bodensatz mit mehr oder weniger breiter hämolytischer Zone bildenden Blut abpipettiert und dann verwendet wurde. Als Blutfarbstoff kam entweder eine 
Lösung von Erythrocyten verschiedener Tierarten oder käufliches Oxyhämoglobin und schließlich auch je nach der Versuchsanordnung unveränderte Erythrocyten zur Anwendung; zu einem Kubikzentimeter dieser Bouillonkultur wurdo ein Tropfen einer willkürlich gewählten Blutfarbstoff- oder Blutkörperchenverdünnung zugegeben. Als besonders geeignet erwies sich eine Blutlösung aus 1 Teil Blut und 2 Teilen destillierten Wassers. Die durch den Blutfarbstoff hellrot gefärbte Kultur wurde in den Brutschrank gestellt. Schon nach wenigen Minuten in der Regel nach 5-15 Minuten, änderte die vorher hellrote und im Spektrum nur zwei deutliche Oxyhämoglobinstreifen zeigende Kultur ihren Farbton; sie wurde graubraun bis grünlichgrau, je nach dem Durchmesser des Röhrchens und der Eigenfarbe der Kultur. Spektroskopisch war ein sehr deutlicher Absorptionsstreifen in Rot zwischen den Linien $C$ und $D$, entsprechend einer Wellenlänge von $\lambda=$ ca. 630 zu sehen, ferner zwei Streifen zwischen $D$ und $E$, von denen der eine knapp bei $D(\lambda=580-581)$ und der andere näher an $E$ lag, beide viel schwächer als der erste in Rot gelegene. $\mathrm{Ab}$ und zu war noch ein vierter Absorptionsstreifen in Blau, bei $F(\lambda=u m 500)$; in den meisten Fällen war jedoch dieser ganze Anteil des Spektrums nicht zu sehen, was be sonders dann der Fall war, wenn die spektroskopische Untersuchung nicht in engen, sondern in breiten Glasgefäßen, also in dicker Schicht vor sich ging. Von diesen Streifen kommt bekanntlich dem in Rot gelegenen $(\lambda=630)$ die Hauptbedeutung für die Erkennung des Methämoglobins in Betracht. DaB es sich tatsächlich um Methämoglobin und nicht etwa um das wegen des ähnlichen spektroskopischen Bildes in Frage kommende Hämatin handle, zeigte ein einfacher Versuch mit Ammoniumsulfat, nach dessen Zusatz im Spektroskop nicht die charakteristischen Streifen des reduzierten Hämatins, sondern der breite Streifen des reduzierten Hämoglobins zu sehen war. Hinzugefügt sei hier, daß die untersuchte Bouillonkultur in der Regel gegen Lackmus neutral oder schwach sauer reagierte. Die Feststellung der Reaktion hat insofern eine gewisse Bedeutung, als sie - wie dies schon Grüter hervorgehoben hat - zeigt, daß nicht etwa die gebildete Säure die Methämoglobinbildung verursacht. Denn erstens genügt der etwa vorhandene Säuregrad nicht zur Bildung von Methämoglobin, zweitens erfolgt letztere auch bei neutraler oder schwach alkalischer Reaktion des Mediums. $\mathrm{Zu}$ viel Alkali vermag allerdings die Methämoglobinbildung zu verhindern ( $Z$ angenmeister). Zwischen den bei der Methämoglobinbildung durch Pneumokokken äußerlich und spektroskopisch wahrnehmbaren Veränderungen und dem Alkalescenzgrad des Mediums besteht ferner ein Zusammenhang folgender Art:

Wird zu der nach Zusatz von Blutfarbstoff hellrot gefärbten und sich bald verfärbenden Flüssigkeit eine Spur Alkali zugefügt und die 
Reaktion gegen Lackmus alkalisch gemacht, dann tritt sofort dunkelrote Färbung, die manchmal - wenn zu viel Alkali genommen wird bald hellbraun wird. Im Spektrum sieht man dann Veränderungen je nach dem Alkalescenzgrade: allmähliches Verblassen des ersten Streifens in Rot, bei gleichzeitigern Hervortreten eines neuen ganz blassen Absorptionsstreifens neben dem bei der $D$-Linie gelegenen, wobei die zwei zwischen $D$ und $E$ gelegenen Streifen deutlicher werden. Von den zwei letzteren ist der zweite (nach dem violetten Anteil des Spektrums gelegene) breiter als der erste, im Gegensatz zu ihrem Verhalten beim Oxyhämoglobin. Wenn man also sehr wenig Alkali zusetzt, kann man unter Umständen gleichzeitig fünf Absorptionsstreifen sehen, und zwar den noch sichtbaren in Rot, den des neutralen oder sauren Methämoglobins, den neu auftretenden des alkalischen Methämoglobins bei $D$, die zwei zwisehen $D$ und $E$ gelegenen und schließlich, wenn überhaupt schon früher vorhanden, einen fünften in Blau. UUberschreitet die Alkalisierung einen bestimmten Grad, dann setzen noch weitere Veränderungen ein, auf die jedoch hier nicht weiter eingegangen werden soll.

Sehr instruktiv erwies sich die Beobachtung der Methämoglobinbildung im Bürkerschen Vergleichsspektroskop. Dieses Instrument gestattet bekanntlich die gleichzeitige Untersuchung zweier Lösungen. Wurde nun in eine Cuvette die durch die Pneumokokken verfärbte Lösung und in die andere eine mittels Ferricyankalium hergestellte Methämoglobinlösùng gegossen, dann konnte man im Spektroskop eine vollkommene Identität der Absorptionsbilder wahrnehmen. Ebenso ließen sich die Lagebeziehungen der Absorptionsstreifen des durch Pneumokokken veränderten und des unveränderten Blutfarbstoffes studieren.

Hierauf wurden die näheren Bedingungen der Methämoglobinbildung durch Pneumokokkenkulturen untersucht, wie die Bedeutung der Kulturmenge, der Einwirkungsdauer, der Temperatur, der Konzentration der Blutflüssigkeit, der Art des Blutfarbstoffzusatzes (gelöste Erythrocyten oder nicht), die Bedeutung der Tierspezies, von der das Blut herrührte, des Sauerstoffs usw. Auf die in Ubereinstimmung mit den diesbezüglichen Befunden von Dittrich, Grüter und von Cole Ruf us beim Studium der Methämoglobinbildung durch verschiedene chemische Substanzen bzw. durch Strepto- und Pneumokokken stehenden Versuchsergebnisse, soll nur kurz eingegangen werden.

In zwei Versuchsreihen wurden fallende Mengen ( $1 \mathrm{ccm}$ bis $0,05 \mathrm{ccm}$ ) einer 24 stündigen Bouillonkultur mit steriler Nährbouillon bzw. mit 0,85 proz. NaClLösung auf ein bestimmtes Gesamtvolum (z. B. $1 \mathrm{ccm}$ ) ergänzt, mit I Tropfen einer Blutlösung gemisoht und in die Brutkammer gestellt. Je größer die Kulturmenge war, um so rascher erfolgte Verfärbung, je länger die Beobachtung ausgedehnt wurde, um so kleinere Kulturmengen waren imstande, die hellrote Lösung in eine graubraune oder grünlichgraue umzuwandeln. Jedesmal entsprach dieser Verfärbung die spektroskopisch für Methämoglobin charakteristische Veränderung. 
In der Regel erfolgte auch in den Röhrchen mit der kleinsten angewandten Versuchsmenge $(0,05 \mathrm{ccm})$ nach höchstens einer Stunde Verfärbung, wäbrend sie, wie bereits eingangs erwähnt wurde, bei der Anwendung der unverdünnten Kultur schon nach wenigen Minuten zu sehen war. Die spektroskopisch wahrnehmbare Methämoglobinbildung erfolgte schon relativ viel früher, und zwar konnte fast immer sofort nach Zusatz der Blutlösung zur unverdünnten Kultur ein, wenn auch anfangs schwacher, Absorptionsstreifen in Rot, bei noch sehr deutlichen Oxyhämoglobinstreifen, also sofort beginnende Methämoglobinbildung wahrgenommen werden. Erst allmählich stellte sich vollständige Verfärbung ein.

Die Verwendung von Nährbouillon als Ergänzungsflüssigkeit machte sich in der Weise gegenüber der 0,85 proz. NaCl-Lösung geltend, daß dort die Verfärbung rascher erfolgte. Selbstverständlich wurden immer Kontrollen mit steriler Nährbouillon bzw. NaCl-Lösung angesetzt, um zu sehen, ob diese Ergänzungsflüssigkeiten allein nicht imstande sind, nach längerer oder kürzerer Zeit Methämoglobinbildung hervorzurufen. Aus den Versuchen Dittrichs ist bekannt, daß das bei längerer Einwirkungsdauer (24 Stunden) möglich ist. Unter den gegebenen Versuchsbedingungen zeigten die Kontrollen in der Regel keine äußerlich oder spektroskopisch wahrnehmbare Veränderung des zugesetzten Blutfarbstoffes, nur ein einziges Mal zeigte eine Kontrolle mit Fleischextraktbouillon einen zwar schwachen Absorptionsstreifen in Rot $(\lambda=630)$, allerdings erst nach 4 stündiger Bebrütung bei $37^{\circ} \mathrm{C}$. Immerhin ergibt sich aus diesem, wenn auch seltenen Vorkommnis die Wichtigkeit solcher Kontrollen, besonders im Hinblick auf eventuelle, noch zu erörternde Schlußfolgerungen über die Filtrierbarkeit der in Betracht kommenden wirksamen Substanz.

Bei Zimmertemperatur erfolgte die Methämoglobinbildung viel langsamer. als unter sonst gleichen Versuchsbedingungen bei Bruttemperatur, und im Eisschrank erfolgte auch nach tagelanger Beobachtung keine Verfärbung, wohl aber eine spektroskopisch wahrnehmbare Veränderung durch Auftreten eines gerade noch sichtbaren Absorptionsstreifens in Rot, bei gut erhaltenen Oxyhämoglobinstreifen.

Da $B$ die durch unbeschädigte Erythrocyten rot gefärbte Kultur sich relativ langsamer verfärbt als bei Zusatz von gelöstem Blutfarbstoff, ist leicht verständlich, wenn man bedenkt, daB im ersteren Falle die wirksame Substanz die Erythrocytenmembran zuerst durchdringen muß, um zum Blutfarbstoff zu gelangen, vorausgesetzt, daß nicht die Blutkörperchen durch die Pneumokokken aufgelöst werden. Letzteres ist jedoch bei der in Betracht kommenden Versuchsdauer nicht der Fall, zumindest aber läßt es sich mit Sicherheit zeigen, daß die Verfärbung auch bei vollkommen gut erhaltenen Erythrocyten erfolgen kann, was sich ja durch gleichzeitige mikroskopische Untersuchung von Nativpräparaten aus der durch die zugesetzten Erythrocyten zuerst rot und dann graubraun gefärbten Kulturflüssigkeit feststellen läßt. ,Daß aber 
ein Eindringen in das Erythrocyteninnere die Voraussetzung für die Umwandlung des Hämoglobins bildet, dafür spricht die Erfahrungstatsache, daß gewisse, den frei gelösten Blutfarbstoff mit Leichtigkeit in Methämoglobin umwandelnde chemische Substanzen (wie z. B. Ferricyankalium) sich gegenüber erhaltenen Erythrocyten als unwirksam erweisen (Dittrich u. a.). Damit hängt auch die von Grüter u.a. und auch von mir bestätigte Erscheinung zusammen, daß die Erythrocyten verschiedener Tierarten infolge der differenten Permeabilitätsbedingungen den Pneumokokken gegenüber sich hinsichtlich der Dauer bis zum Eintritt der Verfärbung verschieden verhalten. Die durch Pferdeblutkörperchen rot gefärbte Kulturflüssigkeit ändert ihre Farbe langsamer als bei Zusatz von menschlichen oder Kaninchenerythrocyten. Auf diese Beziehungen der wirksamen Substanz zu den Erythrocyten und zu Oberflächen im allgemeinen soll noch weiter unten eingegangen werden.

Die Vermehrung des Blutfarbstoffes oder der Blutkörperchenmenge, die als Indicator der Methämoglobinbildung verwendet wurde, macht sich in einer Verzögerung des äußerlich wahrnehmbaren Verfärbungsprozesses, nicht aber der Methämoglobinbildung bemerkbar, denn spektroskopisch tritt der charakteristische Streifen in Rot nicht verspätet gegenüber einer Probe mit weniger Blutfarbstoff auf.

Nicht ohne Bedeutung war das Alter der Kultur. Dies möge folgender Versuch illustrieren:

Je $1 \mathrm{ccm}$ einer 24-, 48- und 72stündigen Blutbouillonkultur eines Pneumokokkenstammes wird mit 1 Tropfen Blutlösung gemischt und in die Brutkammer gestellt. Naoh 10 Minuten ist äuBerlich keine dentliche Veränderung wahrzunehmen; spektroskopisch zeigt die durch den Blutfarbstoff rotgefärbte 24stündige Kultur außer den zwei Oxyhämoglobinstreifen einen deutlichen Absorptionsstreifen in Rot, die 48stündige einen schwachen und die 72stïndige einen kaum wahrnehmbaren Streifen des Methämoglobins bei $\lambda=630$. Nach 20 Minuten ist die 24stündige Kultur vollkommen graubraun verfärbt und spektroskopisch das gut ausgebildete Methämoglobinspektrum zu sehen; die 48stündige ist rötlichbraun, die 72stündige dunkelrot, beide zeigen einen deutlichen Absorptionsstreifen in Rot. Erst nach 50 Minuten bieten alle drei Proben äußerlich und spektroskopisch das gleiche Aussehen. Die Kontrollen, $1 \mathrm{ccm}$ sterile Nährbouillon und 1 Tropfen Blutlösung enthaltend, bleibt unverändert.

Aus diesem Versuch ist zu ersehen, daß das Methämoglobinbildungsvermögen der Bouillonkulturen (im Gegensatz zu den relativ länger wirksamen Kulturen auf festen Nährböden) mit dem Alter der Kultur abnimmt. Es wäre jedoch voreilig, wollte man aus diesem Versuchsergebnis den direkten Schluß ableiten, daß die Methämoglobinbildung an das Leben der Pneumokokken und diese selbst gebunden ist. Der Zusammenhang zwischen beiden ist zwar nicht zu verkennen: impft man von den Bouillonkulturen verschiedenen Alters ab, dann überzeugt man sich, daß die Zahl der noch lebensfähigen Keime stark ab- 
nimmt. Haben die Kulturen ein gewisses Alter erreicht - bei der Mehrzahl der untersuchten Stämme waren es 5-7 Tage -, dann gelingt es nicht mehr, Kolonien zu erzielen. Solche Kulturen haben aber noch in der Regel die Fähigkeit, zugesetztes Hämoglobin in Methämoglobin umzuwandeln. Einzelne dieser Kulturen sind allerdings noch imstande, Mäuse zu infizieren; es verbleiben aber dann noch solche, die auch im Tierversuch ein negatives Resultat ergeben und dennoch das Methämoglobinbildungsvermögen besitzen, wenn auch in einem quantitativ stark verringerten Maße. Es ist also das Methämoglobinbildungsvermögen der jüngeren Kulturen ein größeres als bei den älteren, jedoch findet sich das wirksame Agens auch in der nicht mehr lebensfähigen flüssigen Kultur (s. auch Grüter). Im Anschluß an die letzterwähnte Erscheinung ergaben Versuche mit. von festen Nährböden abgeschwemmten Kulturen, ferner Versuche über das Verhalten der durch thermische oder desinfektorische Eingriffe beeinträchtigten Kulturen, die im flüssigen Medium und auf festen Nährböden gezüchtet wurden, wichtige Anhaltspunkte für die Annahme eines freien Produktes der Pneumokokken.

Die auf festen Nährböden gewachsenen Pneumokokken verhalten sich im allgemeinen dem Blutfarbstoff gegenüber ähnlich wie die Bouillonkulturen; es besteht nur ein gradueller Unterschied, insofern als die abgeschwemmten Kulturen zur Umwandlung des Hämoglobins relativ mehr Zeit benötigen als die Bouillonkulturen. Bei den betreffenden Versuchen wurde natürlich darauf geachtet, daß nicht etwa durch Differenzen in der Keimzahl ein verschiedenes Verhalten vorgetäuscht wurde. Es wurden deswegen die Abschwemmungen von den festen Nährböden so hergestellt, daß im hängenden Tropfen der Abschwemmung viel mehr Keime enthalten waren als in dem Tropfen der Bouillonkultur. Besonders deutlich war die Verschiedenheit im Verhalten der Kulturen von festen Nährböden einerseits und der Bouillonkulturen andererseits gegenüber dem Hämoglobin, wenn nicht gelöster Blutfarbstoff, sondern erhaltene Erythrocyten zugesetzt wurden, wie aus folgendem Versuche hervorgeht:

Je eine Reihe mit fallenden Mengen ( $1 \mathrm{ccm}$ bis $0,05 \mathrm{ccm}$ ) einer 24stündigen Blutbouillonkultur bzw. einer dichten Aufschwemmung von auf Löfflerserum nach 24 Stunden gewachsenen Pneumokokken mit steriler Nährbouillon als Aufschwemmungs- und Ergänzungsflüssigkeit wird bei einem Gesamtvolumen von $1 \mathrm{ccm}$ mit je einem 'Tropfen einer dichten Suspension gewaschener Erythrocyten gemischt und in die Brutkammer $\left(37^{\circ} \mathrm{C}\right)$ gestellt. Nach 10, 15, 30 Minuten usw. dehnt sich die Verfärbung in der mit Bouillonkultur angesetzten Reihe auf immer kleinere Kulturmengen aus, während die Röhrchen mit Bakterienaufschwemmung zu dieser Zeit noch unverändert sind. Erst nach $1 \frac{1}{2}$ Stunden zeigen die drei ersten Röhrchen mit den größten Mengen Pneumokokkenaufschwemmung ( $1 \mathrm{ccm}, 0,9 \mathrm{ccm}$ und $0,8 \mathrm{~cm}$ ) braunrote Verfärbung; von den übrigen Röhrchen dieser Reihe zeigen nur die nächsten drei $(0,7,0,6,0,5)$ spektroskopisch einen mehr oder weniger deut- 
lichen Streifen in Rot, während in der Bouillonkulturreihe sämtliche Proben verfärbt sind und das charakteristische spektroskopische Bild bieten.

Es ist also aus diesem Versuch zu ersehen, daß die frisch vom festen Nährboden abgeschwemmte Kultur das Methämoglobinbildungsvermögen gegenüber dem in unversehrten Erythrocyten enthaltenen Blutfarbstoff in geringerem Maße besitzt als die Bouillonkultur gleichen Alters, und zwar trotzdem die Zahl der Pneumokokken in der Aufschwemmung größer ist als in der flüssigen Kultur. Dieser Unterschied verwischt sich jedoch allmählich, je länger man die Kulturaufschwemmung vom festen Nährboden stehen läBt, besonders bei Anwendung von Bruttemperatur $\left(37^{\circ}\right)$. Auch gewährt obiges Versuchsergebnis einen gewissen Einblick in die Beziehungen zwischen wirksamer Substanz und Bakterienleib. Wic bereits früher ausgeführt wurde, ist für die Methämoglobinbildung bei Anwendung unbeschädigter Erythrocyten Voraussetzung, daß̉ die wirksame Substanz die Zellmembran durchdringt. Die Bedingungen hierfür sind anscheinend bei Verwendung von einer flüssigen Kultur, in der sich das wirksame Agens außerhalb der Bakterienleiber befindet, günstiger als bei Anwendung einer frischen Bakterienaufschwemmung, wo sich das methämoglobinbildende Produkt anfangs nur in der Oberfläche oder im Innern der Pneumokokken findet. In letzterem Falle muß das anfangs in der Aufschwemmungsflüssigkeit gar nicht oder in ungenügender Menge vorhandene Agens allmählich erscheinen. Daher ist auch eine längere Einwirkungsdauer notwendig.

Für eine Anreicherung der wirksamen Substanz in der Oberfläche der auf festem Nährboden gewachsenen Pneumokokken spricht die bereits von Cole Ruf us konstatierte und von mir bestätigte Tatsache, daß die gewaschenen Pneumokokken sich noch weniger oder gar nicht zu Methämoglobinbildung eignen. Allerdings stellt sich diese Eigenschaft vollkommen wieder her, wenn man zu den gewaschenen und in Kochsalzlösung aufgeschwemmten Pneumokokken, die in diesem Falle gar kein Methämoglobin zu bilden vermögen, geringe Mengen einer den Stoffwechsel der Bakterien anregenden Substanz z. B. Dextrose zusetzt (Cole).

Im Zusammenhang mit obiger Feststellung, daß die Bouillonkultur verhältnismäßig rascher und intensiver Methämoglobin zu bilden vermag als eine Aufschwemmung vom festen Nährboden, sei darauf hingewiesen, daß die daraus abgeleitete Schlußfolgerung über das Vorhandensein von freien methämoglobinbildenden Produkten in der Bouillonkultur außerhalb der Bakterienleiber nicht vollkommen bindend sein muß. Denn der Umstand, daß zum Versuch ein Uberschuß von Pneumokokken in der Aufschwemmung vom festen Nährboden genommen wird, involviert eine Fehlerquelle. Wie weiter unten bei Be- 
sprechung der Bedeutung des Sauerstoffs für den Vorgang der Methämoglobinbildung durch die Pneumokokken und ihre Produkte gezeigt werden soll, wird diese Methämoglobinbildung von einer entgegengesetzt gerichteten Funktion der Pneumokokken, und zwar der Reduktion begleitet, die unter Umständen so weit gehen kann, daß bereits gebildetes Methämoglobin wieder in Hämoglobin zurückverwandelt wird. Es könnte also die Verzögerung der Methämoglobinbildung durch die Bakterienaufschwemmung gerade durch den Uberschuß an Pneumokokken und die dadurch verursachten stärkeren Reduktionsvorgänge bedingt werden. Diesem Einwand läßt sich durch die auf andere Weise feststellbare Tatsache begegnen, daß das wirksame Produkt auch außerhalb der Pneumokokkenleiber in der Bouillonkultur sich findet (s. weiter unten).

Vom Verhalten gegen Desinfektionsmittel und höhere Temperaturen konnte ebenfalls Aufschluß darüber erwartet werden: im ersteren Falle, also bei Anwendung von Desinfektionsmitteln, müßte die Methämoglobinbildung durch Bouillonkulturen ungehindert vor sich gehen, wenn die wirksame Substanz auch außerhalb der Bakterienleiber sich findet; sie müßte dagegen ausbleiben, falls die Methämoglobinbildung nur eine Funktion der lebenden Zelle ist; bei Anwendung von durch böhere Temperaturen geschädigten Pneumokokken wäre ein gleiches Ergebnis zu erwarten, vorausgesetzt, daß durch die Erhitzung die wirksame Substanz nicht zerstört würde. Auch müßte die Differenz zwischen der Bouillonkultur und der durch Abschwemmen vom festen Nährboden frisch gewonnenen bei diesen Versuchen besonders deutlich hervortreten. Tatsächlich ergaben die betreffenden Versuche verwertbare Resultate - mit gewissen, noch zu erwähnenden Einschränkungen.

Als Desinfektionsmittel wurden aus naheliegenden Gründen Optochin und ein gallensaures Salz genommen. Mit Rücksicht auf die an anderer Stelle ${ }^{1}$ ) mitgeteilten Beziehungen zwischen Keimzahl und Wirksamkeit des Optochins wurde zuerst im Vorversuche jene kleinste Menge Bouillonkultur oder einer Aufschwemmung vom festen Nährboden festgestellt, die nach einer bestimmten Zeit, z. B. nach 2 Stunden, einen Tropfen Blutlösung vollkommen zu verfärben vermochte.

Vorversuch: Fallende Mengen ( $1 \mathrm{ccm}$ bis $0,05 \mathrm{ccm}$ ) einer 24stündigen Blutbouillonkultur von Pneumokokken in einer Reihe, bzw. von einer Aufschwemmung einer Kultur auf Löfflerserum in 0,85 proz. NaCl-Lösung in einer zweiten Reihe, werden mit steriler Nährbouillon bzw. Kochsalzlösung auf ein Gesamtvolumen von $1 \mathrm{ccm}$ aufgefüllt, mit 1 Tropfen Blutlösung gemischt und in die Brutkammer gestellt. Nach 2 Stunden wird abgelesen. In der ersten Reihe (Bouillonkultur) erstreckt sich nach dieser Zeit die Verfärbung bis auf das vorletzte Röhrchen $(0,1 \mathrm{ccm}$ Bouillonkultur), während spektroskopisch auch das letzte Röhrchen $(0,05 \mathrm{ccm})$ einen Streifen in Rot zeigt; in der zweiten Reihe (Pneumokokkenauf-

1) Biochem. Zeitschr. 108, 1920. 
schwemmung) sind die ersten 7 Röhrchen ( $1 \mathrm{ccm}$ bis $0,4 \mathrm{ccm}$ ) verfärbt. Die kleinste Menge, die also nach 2 Stunden einen Tropfen Blutlösung vollkommen zu verfärben vermochte, beträgt für die Bouillonkultur 0,1 ccm, für die Aufschwemmung in Kochsalzlösung 0,4 ccm. Mit diesen Kulturmengen werden nun Parallelversuche mit Optochin und glykocholsaurem Natrium ausgeführt.

Ha uptversuch (Bouillonkultur-Optochin): die Bouillonkultur wird mit steriler Nährbouillon so verdünnt, daß in $1 \mathrm{ccm} 0,1 \mathrm{ccm}$ Kultur enthalten sind, also $10 \mathrm{fach}$. Mit dieser Bouillonkulturverdünnung werden Optochinverdünnungen mit abnehmender Konzentration von 1 : 1000 bis 1 : 10 Millionen hergestellt, zu jedem, $1 \mathrm{ccm}$ enthaltenden Röhrchen 1 Tropfen Blutlösung hinzugefügt und alle Proben in die Brutkammer gestellt. Mehrere Röhrchen mit der gleichen Kulturmenge und einem Tropfen Blutlösung, jedoch ohne Optochin, ferner eine Anzahl von Röhrchen mit Optochinlösung und Blutzusatz, jedoch ohne Kultur, dienen als Kontrollen. Nach 2 Stunden erfolgt Ablesung: mit Ausnahme der Kontrollen, die verschiedene Optochinverdünnungen mit Blutzusatz, jedoch ohne Pneumokokkenbouillonkultur, enthalten und die unverändert sind, zeigen alle anderen Röhrchen, also die Kontrollen mit Bouillonkultur ohne Optochin und die optochinhaltigen Röhrchen mit Bouillonkultur und zwar auch die mit der stärksten Optochinkonzentration, eine mehr oder weniger weit vorgeschrittene braunrote Verfärbung und spektroskopisch die für das Methämoglobin charakteristischen Absorptionsstreifen.

Verfolgt man den Vorgang der Verfärbung zu verschiedenen Zeiten während des Aufenthaltes der Röhrchen in der Brutkammer, also z. B. nach 20, 40, 60 Minuten usw., dann kann man beobachten, daß die Verfärbung zuerst in den Kontrollen ohne Optochin und in den schwächsten Optochinkonzentrationen erfolgt und sich allmählich auf die Röhrchen mit höherem. Optochingehalt ausdehnt. Und auch nach 2 Stunden zeigen die Proben mit mehr Optochin einen relativ geringeren Grad von Verfärbung als die mit schwachen Optochinkonzentrationen, was sich auch spektroskopisch in den verschieden stark ausgebildeten Absorptionsstreifen in Rot kundgibt.

Es folgt aus diesem Versuch, daß das sonst auch in hohen Konzentrationen auf die Pneumokokken stark entwicklungshemmend wirkende Optochin nicht imstande ist, selbst in relativ starken Konzentrationen das Methämoglobinbildungsvermögen der Bouillonkulturen dieser Mikroorganismen zu beeinträchtigen. Dieses Versuchsergebnis ist in weitgehendem 'Maße geeignet, die Annahme, daß in den Bouillonkulturen die methämoglobinbildende Substanz sich auch außerhalb der Pneumokokkenleiber befindet, zu bekräftigen. Die geringen Unterschiede zwischen den Kulturkontrollen ohne Optochin und den optochinhaltigen Kulturproben, ferner zwischen den Kulturproben mit verschiedenem Optochingehalt untereinander wären darauf zurückzuführen, daß das Methämoglobinbildungsvermögen der Bouillonkulturen, welches aus der Summation der Wirkung des freien Produktes und der Pneumokokkenleiber resultiert, durch Einwirkung des Optochins auf die lebenden Mikroorganismen selbst eine gewisse Beeinträchtigung erleidet. 
Daß nicht etwa die Optochinunempfindlichkeit der angewandten Stämme dieses Ergebnis bewirkte, konnte auf einfache Weise durch Beobachtung des Einflusses des Optochins auf eine an die lebenden Mikroorganismen gebundene Funktion, und zwar auf das Reduktionsvermögen der Pneumokokken Methylenblau gegenüber, wie das bereits an anderer Stelle näher beschrieben wurde (1. c.), festgestellt werden. Ließ man auf die im Vorversuche festgestellte Dosis minima reducens, d. h. jene kleinste Kulturmenge, die nach 2 Stunden einen Tropfen einer bestimmten Methylenblaulösung entfärbte, Optochinverdünnungen verschiedener Konzentrationen bei $37^{\circ} \mathrm{C}$ einwirken, dann konnte man sich überzeugen, daß selbst Optochinkonzentrationen von $1: 10$ bis $1: 20$ und auch 1:30 Millionen imstande waren, das Reduktionsvermögen der Pneumokokken Methylenblau gegenüber zu hemmen, zu einer Zeit, wo die Kontrollen ohne Optochin bereits entfärbt waren.

Die in analoger Weise mit von Löfflerserumplatten abgeschwemmten Pneumokokken ausgeführten Versuche zur Feststellung der Beeinflussung ihres Methämoglobinbildungsvermögens durch Optochin ergaben ein ähnliches Resultat wie mit Bouillonkulturen. Die erwarteten Differenzen im Vergleich zum Verhalten der Bouillonkulturen waren nur bei einzelnen Stämmen bemerkbar, d. h., nur die Aufschwemmungen einzelner Stämme erwiesen sich empfindlicher als die dazugehörigen Bouillonkulturen. Es bestehen da, wie es scheint, nicht unwesentliche Differenzen zwischen dem Abtötungs- (Desinfelktions-) und Entwicklungshemmungs- (antiseptischen) Vermögen des Optochins dem Pneumococcus und Str. mucosus gegenüber, worauf jedoch hier nicht näher eingegangen werden soll.

Auch die entsprechenden Versuche mit glykocholsaurem Natrium ergaben, daß das Methämoglobinbildungsvermögen der Pneumokokkenbouillonkulturen durch Konzentrationen dieses gallensauren Salzes nicht wesentlich alteriert wird, in denen andere, an das Leben der Keime geknüpfte Funktionen beeinträchtigt werden. Die Resultate mit konzentrierten Lösungen des glykocholsauren Natriums sind jedoch nicht verwertbar, da diese allein schon imstande sind, das Oxyhämoglobin in andere Modifikationen umzuwandeln.

Das Verhalten gegen höhere Temperaturen wurde sowohl an Bouillonkulturen als auch an Absehwemmungen vom festen Nährboden beobachtet. Das Erhitzen auf $100^{\circ} \mathrm{C}$ im Wasserbade hat sich bei der Blutbouillonkultur insofern unangenehm bemerkbar gemacht, als die eiweißhaltige Flüssigkeit bei dieser Temperatur koagulierte. Dennoch war das Resultat ein derartiges, daß es eine bestimmte Schlußfolgerung zuließ. Folgender Versuch zeigt das:

Acht 24stündige Kulturen auf Löfflerserumplatten $(4,5 \mathrm{~cm}$ im Durchmesser $)$ werden mit insgesamt $12 \mathrm{com} \mathrm{NaCl}-\mathrm{Lösung}$ abgeschwemmt. Von dieser Auf- 
schwemmung werden je $3 \mathrm{ccm}$ im Wasserbade bei $55^{\circ}, 80^{\circ}$ und $100^{\circ} \mathrm{C}$ eine halbe Stunde erhitzt. Nach Abkühlung wird je $1 \mathrm{ccm}$ der unerhitzten und der bei ver. schiedenen Temperaturen erhitzten Aufschwemmung mit je einem Tropfen Blutlösung versetzt und in die Brutkammer $\left(37^{\circ} \mathrm{C}\right)$ gestellt. Nach einer halben Stunde ist die nicht erhitzte Aufsehwemmung vollkommen verfärbt, die eine halbe Stunde bei $55^{\circ} \mathrm{C}$ erhitzte ist äußerlich wenig verändert, zeigt aber spektroskopisch außci den zwei noch gut sichtbaren Oxyhämoglobinstreifen einen schwachen in Ro's $(\lambda=630)$, während die Röhrchen mit der bei $80^{\circ} \mathrm{C}$ bzw. $100^{\circ} \mathrm{C}$ erhitzten Aufschwemmung unverändert sind. Nach 90 Minuten ist die bei $55^{\circ}$ erhitzte Aufschwemmung vollkommen verfärbt, während die zwei andern auch nach mehreren Stunden makro- und spektroskopisch sich nicht verändert haben.

Es erhellt aus diesem Versuche, daß halbstündiges Erhitzen im Wasserbade bei $55^{\circ}$ das Methämoglobinbildungsvermögen einer Pneumolkokkenaufschwemmung vom festen Nährboden wohl abzuschwächen, nicht aber aufzuheben vermag; dagegen bewirkt halbstündiges Erhitzen im Wasserbade bei $80^{\circ}$ und $100^{\circ}$ Verlust dieser Eigenschaft. Der Vollständigkeit halber sei erwähnt, daß die erste Aufschwemmung (55\%) ihre Pathogenität für weiße Mäuse noch behalten hat.

Anders aber fiel ein gleichartiger Versuch mit Bouillonkulturen aus. Auch hier war eine Verzögerung der Methämoglobinbildung die Folge der halbstündigen Erhitzung im Wasserbade bei $55^{\circ}$. Jedoch vermochte halbstündiges Erhitzen auf $80^{\circ}$ und $100^{\circ}$ das Methämoglobinbildungsvermögen nicht vollkommen aufzuheben: es erfolgte, wenn auch erst nach 2 Stunden, eine geringe Verfärbung der durch einen Tropfen Blutlösung gefärbten und vom koagulierten Eiweiß befreiten Kulturflüssigkeit und Auftreten cines schwachen Absorptionsstreifens in Rot, während eine Kontrolle mit erhitzter steriler und dann abgekühlter Bouillon den zugesetzten Blutfarbstoff unverändert ließ.

Die Gegenüberstellung der zwei letzten Versuche würde also ebenfalls den Schluß gestatten, da $\beta$ das methämoglobinbildende Produkt sich auch außerhalb der Pneumokokkenleiber befindet und daß es hitzebeständig ist. Immerhin wäre noch cinem Einwand zu begegnen, und zwar dem, daß durch das Erhitzen die Nährbouillon, in der die Pneumokokken gewachsen sind, methämoglobinbildende Eigenschaften angenommen hat, wenn auch die entsprechende Kontrolle mit unbeimpfter erhitzter Bouillon diese Eigenschaft nicht erwirbt. Dieser Einwand läßt sich nur durch den Nachweis der Filtrierbarkeit der wirksamen Substanz widerlegen. DaB dies möglich ist, zeigt folgender Versuch:

Eine 24stündige Blutbouillonkultur von Pneumokokken wird durch ein steriles Reichelfilter geschickt. Das vollkommen klare Filtrat zeigt die Farbe einer blassen Nährbouillon. Die sofortige spektroskopische Untersuchung ergibt die Abwesenheit von Oxy- und Methämoglobinstreifen. Nun wird $1 \mathrm{ccm}$ des Filtrates mit einem Tropfen Blutlösung versetzt und in die Brutkammer $\left(37^{\circ} \mathrm{C}\right)$ gestellt. Nach einer halben Stunde ist bei dem äußerlich wenig veränderten Aussehen der Lösung im Spektroskop ein zarter Streifen in Rot $(\lambda=630)$ und außerdem zwei deutliche Oxyhämoglobinstreifen wahrzunehmen. Nach 70 Minuten zeigt die vorher hell- 
rote Probe eine dunkelrote Farbe und spektroskopisch den deutlichen Methämoglobinstreifen in Rot und nach 2 Stunden ist die Lösung braun verfärbt. Eine Kontrolle mit steriler Bouillon ließ nach dieser Zeit den Blutfarbstoff unverändert. Vom Filtrat wurden zur Prüfung der Sterilität mehrere Bouillonkulturen angelegt und zwei weiße Mäuse geimpft. Auch nach längerer Beobachtung zeigen die Bouillonröhrchen kein Wachstum und die Mäuse keine Krankheitserscheinung; cbenso bleiben Kulturen aus dem Schwanzblut der Mäuse steril.

Dieser Versuch ergibt also unzweideutig, daß das methämoglobinbildende Produkt der Pneumokokken sich auch a u Berhalb der Bak: terienleiber findet und filtrierbar ist. Nicht zu verkennen ist immerhin der geringe Gehalt des Filtrats an wirksamer Substanz. Denn während eine durch einen Tropfen Blutlösung rotgefärbte Bouillonkultur in 5-15 Minuten sich verfärbt, erfolgt bei Anwendung des Kulturfiltrates die Ausbildung eines Methämoglobinstreifens nach 30 Minuten und vollkommene Verfärbung erst nach 2 Stunden. Dieser geringe Gehalt des Filtrats an wirksamer Substanz könnte entweder daher rühren, daß in der Bouillonkultur wenig freies wirksames Produkt vorhanden ist oder dadurch bedingt sein, daß es beim Passieren des Filters adsorbiert wird. Für die erste Annahme sprechen keine besonderen Gründe; im Gegenteil deuten die früher angeführten Versuche darauf hin, daß in der Bouillonkultur relativ viel freies methämoglobinbildendes Agens vorhanden ist. Hingegen spricht für eine ausgiebige Adsorption in den Filterporen die ziemlich stark ausgesprochene Oberflächenaktivität der wirksamen Substanz, die ja auch darin zum Ausdruck kommt, daß sie auf unversehrte Ery throcyten einzuwirken vermag. Auch kann man sich davon durch Adsorptionsversuche mit gewaschenen Blutkörperchen oder mit Tierkohle leicht überzeugen. Mit dieser Oberflächenaktivität des methämoglobinbildenden Produktes der Pneumokokken steht wahrscheinlich auch eine andere Erscheinung im Zusammenhang, die kurz besprochen werden soll; es ist dies die antagonistische Beeinflussung des Pneumokokkenhämolysins durch das methämoglobinbildende Agens.

Centanni (zitiert bei Přibram) meinte, die Hämolyse durch Pneumokokken würde in der Art erfolgen, daß die Mikroorganismen das „Hämoglobin" (?) zuerst auflösen und es dann in Flocken von rostbrauner Farbe fällen. Wie aber bereits höher oben ausgeführt wurde, läßt sich durch fortlaufende Untersuchung von Nativpräparaten einwandfrei feststellen, daß die Methämoglobinbildung auch in den unversehrten Erythrocyten erfolgt, ohne daß bis dahin eine Fällung oder ein Austritt des Hämoglobins aus den Blutkörperchen wahrzunehmen wäre. Später hat Grüter darauf hingewiesen, daß das hämolytische Vermögen der Pneumokokken von ihrer Eigensehaft, Methämoglobin bilden zu können, abzutrennen ist. Für diese Annahme, daß diese zwei Funktionen der Pneumokokken nicht nur voneinander verschieden sind, sondern auch, 
daß das methämoglobinbildende Produkt die Hämolyse ungünstig beeinflußt, lassen sich indirekt Anhaltspunkte gewinnen.

Die auf Blutagarplatten gezüchteten Pneumokokken zeigen bekanntlich schon nach ca. 18 Stunden charakteristische Kolonien, die von einem grünlichen Hof umgeben sind. Dieser grüne Hof entspricht der Methämoglobinbildung durch das, in die nächste Umgebung der Kolonien diffundierende wirksame Produkt der Pneumokokken und ist, wie das bereits andere Autoren (Riec ke, Grü ter) konstatierten, als optische Täuschung zu deuten. Betrachtet man die Kolonien mit einer starken Lupe oder mit einer schwachen trockenen Linse des Mikroskops, dann nimmt man wahr, daß die Erythrocyten in der nächsten Umgebung der Kolonien noch vollkommen gut zu sehen sind. Schon nach weiteren 10-20 und mehr Stunden hellt sich der grüne Hof etwas auf und dementsprechend werden auch die Konturen der den Kolonien benachbarten Erythrocyten unsichtbar; unter Umständen kommt es zur Ausbildung einer schwachen Delle um die Kolonie.

Da nun die Hämolysinbildung durch Pneumokokken in die erste Periode ihres Wachstums fällt, könnte diese Verzögerung der Hämolyse auf eine vorausgegangene Beeinflussung der Erythrocyten durch das methämoglobinbildende Produkt zurückgeführt werden. Diese Vermutung wird noch mehr durch Versuche bekräftigt, bei denen die antihämolytische Eigenschaft der Pneumokokken bei erhaltenem Methämoglobinbildungsvermögen einerseits und nach Verlust desselben andererseits studiert wird. Letzteres läBt sich, wie oben gezeigt wurde, durch Erhitzen einer frischen Aufschwemmung vom festen Nährboden auf 80 oder $100^{\circ} \mathrm{C}$ erreichen. Soll dem methämoglobinbildenden Produkt für die Verzögerung der Hämolyse irgendeine Bedeutung beigemessen werden, dann müßte nach Verlust des Methämoglobinbildungsvermögens diese Verzögerung ausbleiben oder merklich geringer sein. Letzteres ist tatsächlich der Fall.

Die Eigenschaft der Aufschwemmungen lebender Pneumokokken, die Immunhämolyse ziemlich stark zu hemmen, ist relativ besser ausgeprägt als bei einer Reihe anderer Bakterien, wie man sich durch Anstellung von Parallelversuchen unter annähernd gleichen Bedingungen überzeugen kann. Untersucht man nun gleichzeitig diese Eigenschaft bei lebenden und durch Erhitzen ihres Methämoglobinbildungsvermögens beraubten Pneumokokken (Aufschwemmung), dann ist ein Unterschied zugunsten der lebenden unverkennbar. Folgende Versuche demonstrieren das:

Acht 24stündige Pneumokokkenkulturen auf Löfflerserum werden mit insgesamt $20 \mathrm{ccm} \mathrm{NaCl}$-Lösung abgeschwemmt. Davon werden $10 \mathrm{ccm}$ eine halbe Stunde im Wasserbade bei $95^{\circ}$ erhitzt; beide Proben, die unerhitzte und die erhitzte, werden hierauf auf ihre Eigenschaft, die Immunhämolyse zu hemmen, geprüft. Von dem im Vorversuch ausgewerteten Hammelblutamboceptor wird 
die zweifache Titerdosis, vom Komplement, das beim Auswertungsversuch noch in 25 facher Verdünnung wirkte, eine Verdünnung $1: 15$ angewendet. Der Zusatz des hämolytischen Systems erfolgt, nachdem die PneumokokkenkomplementKochsalzmischung eine Stunde bei $37^{\circ}$ gestanden hatte. Mehrere Röhrchen ohne Pneumokokken dienen als Kontrollen (Tab. I und II).

Tabelle I.

\begin{tabular}{|c|c|c|c|c|c|}
\hline . & $\begin{array}{l}\text { Nicht erhitzte } \\
\text { Pneumokokken- } \\
\text { aufschwemm. }\end{array}$ & $\begin{array}{c}\mathrm{NaCl} \\
(0,85 \%)\end{array}$ & Kompl. 1:15 & Amboc. 1:800 & $\begin{array}{c}\text { Hammeleryth. } \\
5 \%\end{array}$ \\
\hline 1. Röhrchen: & $1,0 \mathrm{ccm}$ & - & $0,5 \mathrm{ccm}$ & $0,5 \mathrm{ccm}$ & $0,5 \mathrm{ccm}$ \\
\hline 2. & 0,9, & $0,1 \mathrm{ccm}$ & 0,5, & 0,5, & 0,5, \\
\hline 3. & 0,8, & 0,2, & 0,5, & $0,5 \quad$, & 0,5, \\
\hline 4. & 0,7, & 0,3, & $0,5 \quad$, & $\stackrel{\vec{m}}{\sim} 0,5$, & 0,5, \\
\hline 5. & 0,6, & $0,4, "$, & 0,5, & $0,5 \quad$, & 0,5, \\
\hline 6. & 0,5, & $0,5 \quad$, & 0,5, & 0,5, & 0,5, \\
\hline 7. & 0,4, & $0,6 \quad$, & 0,5, & 0,5, & 0,5, \\
\hline 8. & 0,3, & 0,7, & $0,5 \quad$, & 0,5, & $0,5 \quad$, \\
\hline 9. & 0,2, & 0,8, & 0,5, & 0,5, & 0,5, \\
\hline 10. & 0,1, & 0,9, & 0,5, & 0,5, & 0,5, \\
\hline Il. & 0,05, & 0,95, & 0,5, & 0,5, & $0, \tilde{5}$, \\
\hline Kontrolle & - & 1,0, & 0,5, & 0,5, & 0,5, \\
\hline
\end{tabular}

Die Kontrollen ohne Pneumokokken sind nach 15 Minuten vollkommen gelöst, während die Röhrchen mit der Aufschwemmung lebender Pneumokokken zu dieser Zeit ungelöst sind. Nach 20 Minuten zeigt das 11 . Röhrchen $(0,05 \mathrm{ccm}$ Pneumokokkenaufschwemmung) fast komplette Lösung, das 10. fast komplette Hemmung; die übrigen Röhrchen sind vollkommen ungelöst. Nach 60 Minuten sind die Röhrohen 9-11 gelöst, 1-8 ganz gehemmt. Auch nach $1^{1 / 2}$ Stunden ändert sich dieses Verhältnis nicht, nur sind die Röhrchen I-5 mit den höheren Pneumokokkendosen verfärbt.

Anders fällt ein unter sonst gleichen Bedingungen angesetzter Versuch mit der auf $95^{\circ}$ erhitzten Pneumokokkenaufschwemmung (Tab. II).

Tabelle II.

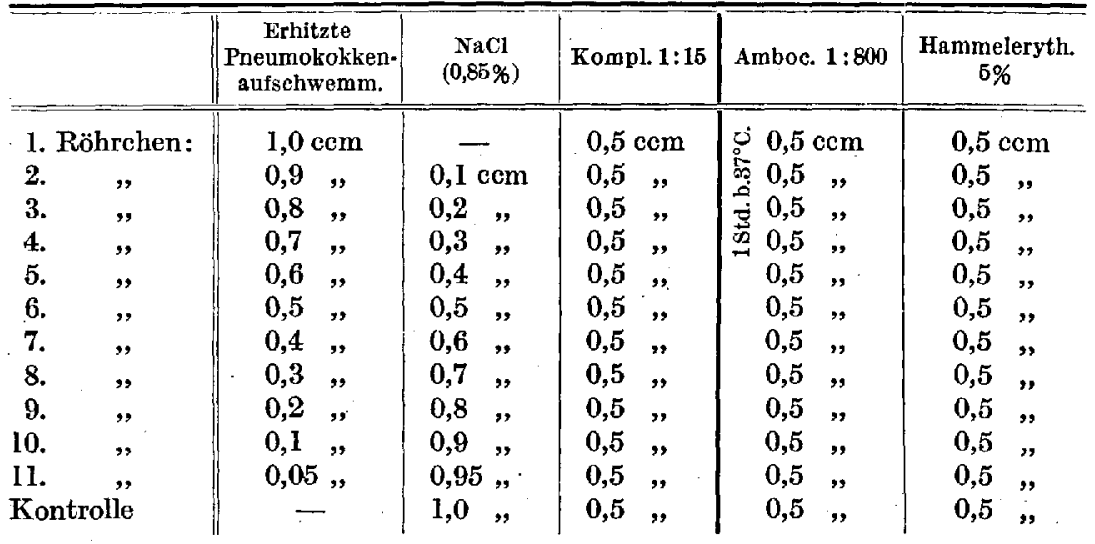


Nach 15 Minuten sind die Kontrollen ohne Pneumokokken gelöst; zu gleicher Zeit zeigt auch das 11. Röhrchen fast komplette Lösung. Nach 20 Minuten ist das 10. Rährchen fast vollkommen gelöst, während das 11. vollständige Hänolyse zeigt. Nach 30 Minuten ist im 10. Lösung erfolgt und nach $11 / 2$ Stunden zeigen das 8. und das 9. komplette Lösung, die Proben 1-7 sind ungelöst und auch in ihrem Farbenton unverändert, was nicht wundernehmen kann, da ja das Methämoglobinbildungsvermögen der Pneumokokkenaufschwemmung durch Erhitzen auf $95^{\circ} \mathrm{C}$ verlorengegangen ist.

Es folgt aus diesen Versuchen, daß das antihämolytische Vermögen der nicht erhitzten Pneumokokkenaufschwemmung größer ist als dasjenige der durch Erhitzen ihrer methämoglobinbildenden Eigenschaft beraubten. Daß das methämoglobinbildende Produkt der nicht erhitzten Pneumokokken an dieser Verzögerung beteiligt ist, läßt sich daraus schließen, daß sie weniger deutlich in Erscheinung tritt, wenn der Zusatz des hämolytischen Systems nicht nach einer Stunde, sondern früher erfolgt, also zu einer Zeit, wo weniger freies Hämoglobingift in der Aufschwemmung vorhanden ist. Natürlich müßte der Nachweis noch geliefert werden, daß diese stärkere antihämolytische Wirkung der nicht erhitzten Aufschwemmung durch eine Beeinflussung der Erythrocyten zustande kommt, was aber nicht leicht möglich ist. Es sei jedoch in dieser Beziehung auf die an anderer Stelle ${ }^{1}$ ) besprochene Bedeutung der Oberflächenaktivität der durch Erythrocytenbeeinflussung antihämolytisch wirkenden Substanzen verwiesen.

Der folgende Abschnitt soll der Besprechung des Mechanismus der Methämoglobinbildung durch Pneumokokken und ihrer Produkte, insbesondere der Bedeutung des Sauerstoffs für diesen Vorgang gelten und im Anschluß daran soll die Bedeutung dieses Phänomens in pathogenetischer Beziehung erörtert werden.

Bekanntlich ist das Methämoglobin eine feste Verbindung des Hämoglobins mit dem Sauerstoff und unterscheidet sich vom Oxyhämoglobin dadurch, daß bei letzterem die Sauerstoffbindung eine lockere ist.

Die genannte feste Verbindung des Sauerstoffs im Methämoglobinmolekül bringt es mit sich, daß diese Blutfarbstoffmodifikation für den Respirationsproze $B$ unbrauchbar ist. Dementsprechend wird die Methämoglobinbildung im wesentlichen als Oxydationsvorgang aufgefaßt. Dittrich hat darauf hingewiesen, daß sich die Rolle des Sauerstoffs beim Vorgange der Methämoglobinbildung auf eine ,vorbereitende Aufgabe beschränkt, und zwar die Ưberführung von Hämoglobin zu Oxyhämoglobin". Dieser Autor zeigte, daß auch für reduzierende Stoffe, wie z. B. Gallussäure, das Oxyhämoglobin eine Vorstufe des Methämoglobins darstellt. Gewisse Schwierigkeiten für das Verständnis des Vorgangs der Methämoglobinbildung ergaben sich aus der Tatsache, daß nicht allein oxydierende Mittel, wie Nitrate, nitrierte organische Substanzen usw., sondern auch reduzierende, wie Pyrogallol, Brenz- 
katechin, Hydrochinon u. a. und schließlich solche, die als indifferent zu bezeichnen sind, imstande sind, Methämoglobin zu bilden. HoppeSeyler zeigte, daß es auch bei lebhaften Reduktionsvorgängen zur Aktivierung des Sauerstoffs kommen kann. In neuerer Zeit konnte von Heubner in exakten Versuchen der Beweis erbracht werden, daß die als Reduktionsmittel bekannten, methämoglobinbildenden Substanzen-durch vorausgegangene Oxydation in Oxydationsmittel übergehen, die dann erst zur Methämoglobinbildung führen.

Heubner untersuchte versehiedene reduzierende Substanzen auf ihr Methämoglobinbildungsvermögen, darunter auch das Aminophenol. Der Vorgang der Methämoglobinbildung durch diese Substanz gleicht möglicherweise demjenigen bei der Methämoglobinbildung durch Pneumokokken und ihre Produkte und soll deswegen kurz erwähnt werden (s. auch Cole). Die von Heubner für den Reaktionsablauf bei der Methämoglobinbildung durch das Aminophenol angegebene Formel lautet:
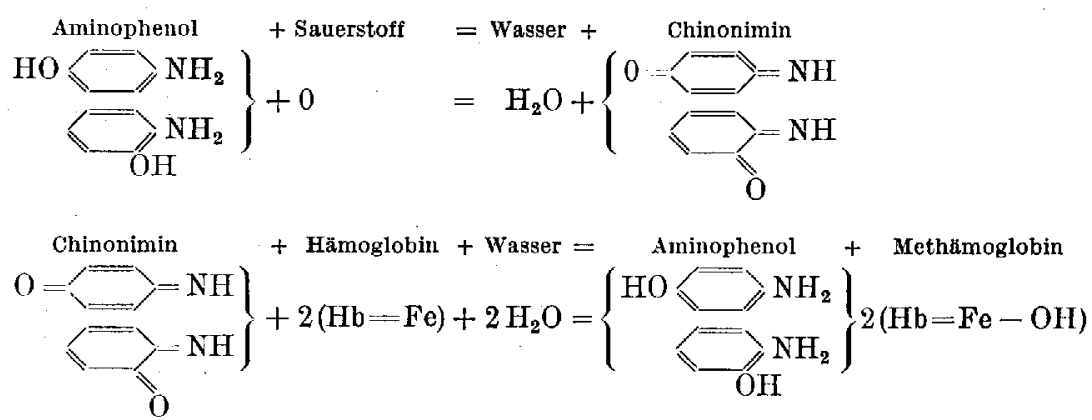

Aus der beigefügten Reaktionsformel folgt, daß das Aminophenol erst durch Aufnahme von Sauerstoff in das wirksame Chinon umgewandelt wird. Daß diese Aufnahme des Sauerstoffs wirklich erst die Voraussetzung für die Bildung von Methämoglobin darstellt, ließ sich in den Versuchen Heubners dadurch beweisen, daß in Abwesenheit von Sauerstoff die Methämoglobinbildung nur durch das sekundär entstehende Chinon, nicht aber durch das Aminophenol allein eintritt. Es ist dabei zu beachten, daß Heubner, in Anlehnung an die Auffassung Küsters das Methämoglobin für eine Blutfarbstoffmodifikation hält, in der sich das Eisen nicht wie im Hämo- und Oxyhämoglobin in zweiwertiger, sondern in dreiwertiger Bindung findet.

Manche Beobachtungen sprechen nun dafür, daß die Methämoglobinbildung durch die Pneumokokken und ihre Produkte in ähnlicher Weise verläuft. Cole konnte schon zeigen, daß die Methämoglobinbildung durch Pneumokokken in Abwesenheit von Sauerstoff ausbleibt, daß aber

1) Zeitschr. f. Immunitätsforsch. u. exp. Therap. 1921. 
in der ersten Phase des Prozesses eine Reduktion stattfindet; denn die Reaktion wird beschleunigt, wenn der Sauerstoff zuerst verdrängt und dann wieder zugeführt wird.

Diese Wichtigkeit des Sauerstoffs für die Methämoglobinbildung durch Pneumokokken läßt sich auf einfache Weise demonstrieren, wenn man den Kontakt der durch Hämoglobin gefärbten Kultur mit dem Sauerstoff der Luft in verschiedener Weise variiert, wie z. B. durch Wahl breiterer und engerer Versuchsröhrchen, durch Utberschichtung mit Paraffinöl, Zusatz von reduktionsbegünstigenden Substanzen, wie Traubenzucker usw., wie aus folgendem Versuch hervorgeht:

Mehrere Reihen mit fallenden Mengen einer 24stündigen Blutbouillonkultur von Pneumokokken werden in engen bzw. weiten Röhrchen mit und ohme Paraffinöl angesetzt; eine Reihe erhält als Zusatz 0,1 ccm einer 2 proz. Traubenzuckerlösung in Nährbouillon. Das Gesamtvolumen der einzelnen Röhrchen beträgt $1 \mathrm{ccm}$ (Nährbouillon als Ergänzungsflüssigkeit), die Rotfärbung erfolgt durch Zusatz von einem Tropfen Blutlösung, die Beobachtung der Methämoglobinbildung nach verschiedenen Zeiten des Aufenthaltes in der Brutkammer $\left(37^{\circ}\right)$. Man bemerkt, $\mathrm{da} B$ sich die Verfärbung allmählich in allen Reihen von den größeren Kulturmengen nach abwärts erstreckt; jedoch besteht zwischen der Reihe der weiten Röhrchen ohne Paraffinöl und ohne Zusatz von Traubenzucker einerseits und den anderen Versuchsröhrchen ein Untersehied: dort erfolgt die Methämoglobinbildung rascher und intensiver. Vergleicht man die gleichweiten Versuchsröhrchen mit und ohne Paraffinöl miteinander, so ist der zeitliche Unterschied im Auftreten der Methämoglobinstreifen und der Verfärbung kein sehr prägnanter; in der Regel besteht nur eine qualitative Differenz der Art, daß die Röhrchen mit Paraffinöl eme vollständig gleichmäßige Verfärbung zeigen, während die Proben ohne Paraffinöl in der untersten Kuppe eine rotviolette Färbung bei sonst vollkommener graubrauner Verfärbung zeigen, und zwar ist diese Verfärbung hier stärker als in den Röhrchen mit Paraffinöl. Der rotvioletten Kuppe entspricht im Spektrum das breite Band des reduzierten Hämoglobins.

Aus diesem Versuch ist also zu ersehen, daß die Methämoglobinbildung durch die Pneumokokken von der Anwesenheit des Sauerstoffs in weitgehendem Maße abhängig ist. Die zuletzt erwähnte qualitative Differenz zwischen den Proben mit und ohne Paraffinöl könnte evtl. für eine Kombination von Reduktions- und Oxydationsvorgängen sprechen.

Im Anschluß hieran sei eine Reaktion erwähnt, die auf den Methämoglobinbildungsmechanismus durch Pneumokokken einiges Licht zu werfen vermag. Es ist dies das Verhalten des durch Pneumokokken gebildeten Methämoglobins gegen Wasserstoffsuperoxyd. Setzt man zu der durch die Pneumokokken braun verfärbten Hämoglobinlösung einen Tropfen einer 3 proz. Wasserstoffsuperoxydlösung, dann tritt sofort hellrote Färbung ein. Spektroskopisch entspricht diesem Farbenwechsel ein Abblassen des Absorptionsstreifens in Rot bis zum vollkommenen Verschwinden desselben und das Hervortreten von zwei Absorptionsstreifen bei $\lambda=590$ und $\lambda=550$. Bei längerem Stehen 
der so veränderten Methämoglobinlösung tritt der Absorptionsstreifen des Methämoglobins in Rot allmählich wieder auf. Bei einem Überschuß von Wasserstoffsuperoxyd setzt sich dieser Umwandlungsprozeß bis zur vollkommenen Entfärbung der Lösung unter lebhafter Entwicklung von Gasblasen fort, wobei gleichzeitig alle Absorptionsstreifen im Spektrum verschwinden. Daß die rote Färbung der vorher graubraunen Lösung nicht etwa auf einen Zusatz von Alkali zurückzuführen ist, ergibt die Reaktionsprüfung des Wasserstoffsuperoxyds: letzteres reagiert wie die meisten im Handel erhältlichen Wasserstoffsuperoxydlösungen gegen Lackmus sauer. Dieses Verhalten gegen Wasserstoffsuperoxyd teilt mit dem durch Pneumokokken umgewandelten Blutfarbstoff auch das durch Ferricyankalium (Kobert, Takayama) und, wie ich mich überzeugen konnte, das durch Pepsin gebildete, nicht aber das durch Formalineinwirkung z. B. erhaltene Methämoglobin.

Die erwähnte Tatsache, daß zur Entstehung des Methämoglobins unter dem Einfluß der Pneumokokken und ihrer Produkte Sauerstoff notwendig ist, bedingt es - neben anderen noch zu besprechenden Falktoren - daß es so schwierig ist, in dem von Pneumokokken überschwemmten Blute Methämoglobin nachzuweisen, worauf schon Grüter und neuerlich amerikanische Autoren (l. c.) aufmerksam machten. Dadurch wäre ja überhaupt die Bedeutung dieser Eigenschaft der Pneumokokken und ihrer Produkte, Methämoglobin zu bilden, in pathogenetischer Beziehung in Frage gestellt. Denn, wie schon eingangs hervorgehoben wurde, lehrt die Erfahrung, daß sich nicht immer Reagensglasversuche und deren Ergebnisse auf die Vorgänge im Organismus übertragen lassen. So gibt es auch unter den als Methämoglobinbildner bekannten Substanzen solche, die zwar im Reagensglas diese Eigenschaft zeigen, nicht aber im tierischen Organismus, ebenso wie es anderer. seits Substanzen gibt, die im Tierkörper methämoglobinbildend wirken, nicht aber im Reagensglas. Die Beobachtung der Methämoglobinbildung durch Pneumokokken im Reagensglas allein könnte also auch keine Schlüsse auf die Vorgänge im Organismus gestatten - wenn nicht Veränderungen im Blute mit Pneumokokken infizierter Menschen und Tiere nachweisbar wären, aus denen die Wirkung der.Pneumokokken und ihrer Produkte im Sinne der Methämoglobinbildung zu ersehen wäre. Solche Veränderungen sind aber unter gewissen Umständen tatsächlich nach. weisbar.

So konnten Peabody, ferner Butterfield und Peabody bei unkomplizierten Fällen von Lobärpneumonie des Menschen, ferner bei Pneumokokkenbakteriämien des Kaninchens eine beträchtliche $\mathrm{Ab}$ nahme der Sauerstoffkapazität des Blutes konstatieren. Es erscheint nicht unwichtig, zu erwähnen, daß Masing und Siebeck bei einer ganzen Reihe von Erkrankungen, die nicht durch Pneumokokken her- 
vorgerufen werden, das Sauerstoffbindungsvermögen des Hämoglobins im Vergleich mit gesunden Menschen als annähernd gleich und konstant gef unden haben.

Die Befunde von Peabody und von Butterfield und Peabody konnten von mir in Tierversuchen bestätigt werden. Die Bestimmung der Sauerstoffkapazität erfolgte colorimetrisch und spektrophotometrisch. Einzelheiten darüber sollen später nach der noch vorzunehmenden Prüfung mittels des Verfahrens von Haldane und Barkrof $t$ gebracht werden. Hier sei nur angeführt, daß darüber hinaus in zwei vo n 30 an weißen Mäusen unter verschiedenen Bedingungen ausgeführten Versuchen im Blute ein ganz zarter Absorptionsstreifen in Rot gesehen werden konnte.

Erste Versuchsserie: Fünf weiße Mäuse erhalten je $0,2 \mathrm{ccm}$ einer 24 stündigen Blutbouillonkultur des virulenten Pneumokokkenstammes ,Zeugin“ intraperitoneal eingespritzt. Schon nach 8 Stunden zeigen vier Mäuse deutliche Krankheitserscheinungen. Zwei von diesen Mäusen wird aus der Schwanzvene je 0,1 ccm Blut entnommen und in $0,4 \mathrm{ccm}$ destilliertes Wasser aufgelöst. Die spektroskopische Untersuchung ergibt nur das Absorptionsbild des Oxyhämoglobins. Hierauf werden diese zwei Mäuse getötet, das Herzblut spektroskopisch angeschaut; auch hier keine Spur eines Methämoglobinstreifens in Rot. Mikroskopisch finden sich spärliche Diplokokken vom Aussehen der Pneumokokken. Von den drei übrigen Mäusen gehen zwei nach insgesamt 18 Stunden, die letzte nach 36 Stunden ein. Bei allen ergibt die sofortige Untersuchung des Herzblutes ein negatives Resultat. Mikroskopisch finden sich mäßig viele Pneumokokken.

Zweite Vers u chsse rie: Fünf weiße Mäuse erhalten je $0,2 \mathrm{ccm}$ einer 24stündigen Blutbouillonkultur des Pneumokokkenstammes ,Zeugin" intravenös eingespritzt. Die intravenöse Injektion erfolgt in die seitliche Schwanzvene nach vorausgegangener Hyperämisierung mittels heißen Wassers und Stauung mit einem Gummibändchen. Die nach 8 und 10 Stunden vorgenommene Untersuchung des Schwanzblutes auf Methämoglobin ergibt ein vollkommen negatives Resultat. Zwei Mäuse gehen 16 Stunden nach der Infektion, die drei andern nach 20 Stunden (in Abständen von 15-60 Minuten) ein. Die sofortige Untersuchung des dunklen Herzblutes ergibt spektroskopisch das Bild des Oxyhämoglobins, mikroskopisch mäßig viele Pneumokokken. Die Untersuchung im Spektroskop erfolgt bei verschieden dicken Schichten, im Maximum bei $1 \mathrm{~cm}$ dicker Schichte. Nun wird die untersuchte Blutlösung in die Brutkammer gestellt. Nach einer halben Stunde ergibt die spektroskopische Untersuchung bei äußerlich wenig veränderter Farbe des Blutes einen schmalen Streife $n$ in $\operatorname{Rot}(\lambda=630)$.

Dritte Versuchsserie: Fünf weißen Mäusen wird je $1 \mathrm{ccm}$ einer 24stündigen Blutbouillonkultur des Pncumokokkenstammes "Zeugin" intravenös eingespritzt. Sämtliche Mäuse reagieren mit starker Dyspnöe und Prostration, erholen sich aber bald. Nach 30 Minuten wird das Schwanzblut spektroskopisch untersucht; der erhaltene Befund ist ein negativer. Schon nach 10 Stunden geht eine von diesen Mäusen ein. Die Untersuchung des in destilliertem Wasser aufgelösten Herzblutes in dicker Schicht $(1 \mathrm{~cm})$ ergibt einen gerade sichtbaren Streifen in Rot; beide Oxyhämoglobinstreifen sind kräftig ausgebildet, der erste (bei $D$ gelegene) zeigt aber eine unscharfe Begrenzung links (gegen den roten Anteil des Spektrums). Mikroskopisch finden sich sehr viele Diplokokken mit Kapseln. Die übrigen vier Mäuse gehen nach 12 bzw. $13^{1} / 2$ und 15 Stunden ein. Im Spektroskop zeigt das Herzblut, vor allem die Oxyhämoglobinstreifen, mikroskopisch reichlich Pneumo- 
kokken. Die untersuchten Blutproben werden dann in die Brutkammer $\left(37^{\circ}\right)$ gestellt. Nach einer halben bzw. einer Stunde ist in zwei der untersuchten Blutproben ein ganz zarter Methämoglobinstreifen in Rot, bei den zwei andern nach 2- bzw. 3stündigem Aufenthalt bei $37^{\circ}$ zu sehen.

Vierte Versuchsserie: Fünf 24stündige Kulturen des Pneumokokkenstammes „Fischer" werden von Löflerserumplatten mit zusammen $8 \mathrm{ccm} 0,85$ proz. Kochsalzlösung abgeschwemmt. Von der so erhaltenen dichten Keimaufschwemmung wird je I ccm fünf weißen Mäusen intravenös eingespritzt. Die im Anschluß daran aufgetretene starke Dyspnöe schwindet bald. Die nach einer halben, nach 4 und 8 Stunden vorgenommene spektroskopische Untersuchung des Schwanzblutes auf Methämoglobin fällt negativ aus. Nach 12 Stunden werden zwei in Agonie befindliche Mäuse getötet. Bei einer von diesen ergibt die spektroskopische Untersuchung des Herzblutes in dicker Schicht einen gerade wahrnehmbaren Streife $n$ in Rot. Bei den drei übrigen während der Nacht eingegangenen Mäusen ergibt die Untersuchung auf Methämoglobin ein negatives Resultat.

Zwei weitere Versuchsserien mit je fünf in ähnlicher Weise vorbehandelten weißen Mäusen fielen ebenfalls hinsichtlich des Methämoglobinnachweises negativ aus.

Bei Kaninchen, die intravenös mit Pneumokokken behandelt wurden und an einer Bakteriämie erkrankten, konnte außer der oben erwähnten Abnahme des Sauerstoffbindungsvermögens niemals ein für Methämoglobin charakteristischer Absorptionsstreifen gesehen werden.

Aus obigen Versuchen ist zu ersehen, daß es nur a us nahmsweise und unter bestimmten Versuchsbedingungen gelingt, im Blute der mit virulenten Pneumokokken infizierten weißen Mäuse ein der Methämoglobinbildung entsprechendes spektroskopisches Bild zu beobachten. Dieser wenn auch seltene positive Befund gestattet aber im Verein mit der in vielen Fällen $\mathrm{z} u$ konstatierenden $\mathrm{Ab}$ nahme des Sauerstoffbindungsvermögens des Blutes, der Fähigkeit der Pneu mokokkenundihrer Produkte, Methämoglobin zu bilden, eine gewisse Bedeutung in pathogenetischer Beziehung beizulegen, falls nicht eine zu geringe Menge Pneumokokken in der Blutbahn eine solche Annahme unwahrscheinlich macht.

Bemerkenswert ist noch in obigen Versuchen die Beobachtung, daß das Herzblut der Mäuse, welches frisch entnommen bei relativ reichlichem Gehalt an Pneumokokken keine besonderen Veränderungen im Spektroskop wahmehmen läßt, nach mehr oder weniger langem Aufenthalt in der atmosphärischen Luft bei $37^{\circ} \mathrm{C}$ den Methämoglobinstreifen in Rot erkennen läßt. Sie wirft ein Licht auf die aus der Toxikologie anderer methämoglobinbildenden Substanzen bekannte Erfahrung, daß sich die charakteristische spektroskopische Veränderung bei manchen Substanzen nur im sauerstoffhaltigen Blute bildet. Diese Tatsache trifft, wie ersichtlich, auch bei der Methämoglobinbildung durch Pneumokokken zu. Dazu kommen noch einige andere Faktoren, die mit der 
genannten Erscheinung zusammenhängen und die nun kurz besprochen werden sollen.

Wenn trotz der Anwesenheit von Pneumokokken im Blute die charakteristische spektroskopische Veränderung nicht nachweisbar ist, so kann es entweder daran liegen, daß zu wenig Methämoglobin vorhanden ist oder daß die Wahrnehmung des vorhandenen Methämoglobins durch gewisse Einflüsse erschwert wird oder daß bereits gebildetes Methämoglobin rasch wieder in Hämoglobin umgewandelt wird oder sonstwie aus der Blutbahn verschwindet.

Damit der Methämoglobinstreifen im Blute gesehen werden kann, ist eine Konzentration des Methämoglobins von $21 \% 2 \%$ notwendig (Erben in Dittrichs Handbuch der Sachverständigentätigkeit); erst dann ist der charakteristische Absorptionsstreifen in Rot eben zu sehen. Diese Wahrnehmung der spektroskopischen Veränderung wird durch die alkalische Reaktion des Blutes ersehwert, wie man sich leicht durch folgenden Versuch überzeugen kann:

Zu $2 \frac{1}{2}$ ccm einer durch Hämoglobinzusatz vorher rot gefärbten und nach halbstündigem Aufenthalt bei $37^{\circ} \mathrm{C}$ stark graubraun verfärbten Pneumokokkenaufschwemmung werden fünf Tropfen klaren, nicht hämolytischen (spektroskopische Untersuchung!) Kaninchenserums zugesetzt. Die graubraune Lösung, die einen deutlichen Absorptionsstreifen in Rot zeigt, färbt sich sofort schwach rot; im Spektroskop tritt eine Abblassung des Methämoglobinstreifens ein. Bei Zusatz von 20 Tropfen desselben Serums ist bereits ein schwacher Schatten links von dem bei $D$ gelegenen Absorptionsstreifen zu sehen, während der Streifen in Rot kaum noch zu sehen ist. Eine Kontrolle (eine durch Pneumokokkenaufschwemmung verfärbte Hämoglobinlösung), der die gleiche Anzahl Tropfen einer indifferenten Flüssigkeit, z. B. Kochsalzlösung zugesetzt wird (Verdünnungskoeffizient), zeigt eine kaum wahrnehmbare Abschwächung des Methämoglobinstreifens.

Es folgt aus diesem Versuche, daß die alkalische Reaktion des Blutserums imstande ist, die Konstatierung des gebildeten Methämoglobins zu erschweren und evtl. unmöglich zu machen. Dazu kommt noch, daß das durch Alkalisierung entstehende alkalische Methämoglobin besonders leicht in Hämoglobin umgewandelt wird (Kobert u. a.). Der ungünstige Einfluß des Serums läßt sich auch schon bei dem Vorgang der Methämoglobinbildung durch Pneumokokken feststellen. Setzt man z. B. in zwei Parallelreihen zu fallenden Mengen Pneumokokkenkultur einerseits sterile Nährbouillon, andererseits das Serum einer beliebigen Tierart hinzu, dann bemerkt man, daß in der Reihe ohne Serum die Methämoglobinbildung bedeutend rascher vor sich geht als in der zweiten mit Serum versetzten. Hier macht sich die alkalische Reaktion des Serums deutlich geltend. Dazu kommt noch der reduktionsbegünstigende Einflu $\beta$ des Serums ohne Rücksicht auf die Reaktion desselben hinzu, was bereits gelegentlich des Studiums des Reduktionsvermögens der Pneumokokken gezeigt werden konnte (l. c.). 
Die leichte Umwandelbarkeit des durch Pneumokokken und ihre Produkte gebildeten Methämoglobins in Hämoglobin infolge der Reduktion durch lebende Zellen (Bakterien, Körperzellen) läßt sich leicht demonstrieren:

Fallende Mengen einer 24stündigen Blutbouillonkultur von Pneumokokken $(0,9$ bis $0,1 \mathrm{ccm})$ werden in je einer Reihe: a) mit Nährbouillon auf ein Gesamtvolumen von $1 \mathrm{com}$ gebracht und mit einem Tropfen Blutlösung gefärbt, b) nach Ergänzung mit Nährbouillon und Zusatz von Hämoglobinlösung mit Paraffinöl überschichtet; c) mit einer gleichgroßen Menge $(0,1 \mathrm{ccm})$ einer frischen Staphylokokkenaufschwemmung gemischt, mit Nährbouillon auf $1 \mathrm{ccm}$ aufgefüllt und mit Hämoglobin gefärbt; d) mit je $0,1 \mathrm{ccm}$ einer frischen Verreibung von Organen beliebiger Tierarten, ebenfalls mit Nährbouillon ergänzt und mit Blutfarbstoff versetzt. Sämtliche Röhrchen kommen in die Brutkammer (37 ${ }^{\circ}$. Die Beobachtung der Methämoglobinbildung in verschiedenen Zeiten ergibt eine beträchtliche Verzögerung in den Reihen c) und d) gegenüber a) und b). Nach insgesamt $2^{1 / 2}$ Stunden sind sämtliche Röhrohen verfärbt und zeigen spektroskopisch einen deutlichen Absorptionsstreifen in $\operatorname{Rot}(\lambda=630)$ neben den zwei mehr oder weniger deutlichen Streifen zwischen $D$ und $E$. Nach weiteren 2 Stunden beginnen sich dic ersten Röhrchen in den Reihen b), c) und d) von unten nach oben rotviolett zu färben, spektroskopisch ist in diesen Proben das breite Absorptionsband des reduzierten Hämoglobins zu sehen. Nur die obersten Anteile der Lösungen in den einzelnen Röhrchen, also an der Berührungsstelle mit der atmosphärischen Luft, zeigen eine bräunliche Verfärbung und dieser entspricht im Spektroskop ein kurzer $A b$ sorptionsstreifen in Rot. Zu dieser Zeit sind die Röhrchen der Reihe a) noch vollkommen graubraun verfärbt. Im Laufe der weiteren Beobachtung dehnt sich die rotviolette Färbung in den Reihen b), c) und d) allmählich auf die Röhrchen mit kleineren Mengen Pneumokokkenkultur aus.

Leitet man mittels einer auf den Boden der rotviolett verfärbten Proben reichenden Glascapillare atmosphärische Luft durch, dann macht die rotviolette Färbung einer hellroten Platz; es hat sich also aus dem reduzierten Hämoglobin Oxyhämoglobin gebildet, was man auch spektroskopisch an den zwei deutlichen Oxyhämoglobinstreifen erkennen kann. Nach einiger Zeit (nach 5 bis mehr Minuten) färbt sich die so behandelte Probe graubraun und zeigt im Spektroskop den Methämoglobinstreifen in Rot außer den nun schwächeren Absorptionsstreifen zwischen $D$ und $E$; nach weiterem Stehen bei $37^{\circ}$ tritt die violette Färbung wieder hervor, es bildet sich also aus dem Methämoglobin neuerlich durch Reduktion reduziertes Hämoglobin. Dieses Spiel kann man beliebig oft wiederholen.

Diese Versuche zeigen, wie sehr das reduzierende Vermögen lebender Zellen und Luftabschluß die Umwandlung von Hämoglobin in Methämoglobin verzögern und, was noch wichtiger ist, die Rückverwandlung des Methämoglobins in Hämoglobin bedingen können. Die Reihen b), c) und d) im obigen Versuch unterscheiden sich voneinander nur quantitativ wenig durch den Gehalt an reduzierender Substanz, dagegen aber wesentlich von der Reihe a), die außer der Nährbouillon keinen besondern Zusatz erhalten hat; die Anwesenheit der reduzierenden Körper in den Reihen b), c) und d) bewirkt, daß hier die Methämoglobinbildung stark verzögert und die Rückverwandlung des Methämoglobins in Hämoglobin erleichtert wird. Beachtenswert ist, daß die rotviolette Verfärbung, d, h. die Rückverwandlung des Methämoglobins in Hämo- 
globin in jeder dieser Reihen (b, $\mathrm{c}$ und d) zuerst in den ersten Röhrchen mit den größeren Mengen Pneumokokken erfolgt; hier treten zu dem Reduktionsvermögen der zugesetzten Zellen (Staphylokokken, Organzellen) die reduzierenden Eigenschaften der Pneumoķokken selbst. Von den verschiedenen Organen erwies sich die Leber, als ein mit starkem Reduktionsvermögen ausgestattetes Organ, besonders geeignet, diese Rückverwandlung des Methämoglobins in Hämoglobin zu begünstigen. Diese Beobachtung der Rückverwandlung des Methämoglobins, die im wesentlichen einem Reduktionsvorgang entspricht, deckt sich mit den Erfahrungen, die bei anderen Methämoglobinbildnern gemacht wurden (Hayem, Filipowski u.a.).

Daß ähnliche Vorgänge im Organismus stattfinden, braucht nicht näher ausgeführt zu werden. Und so erscheint es verständlich, daß, obzwar die Pneumokokken und ihre Produkte ein relativ sehr starkes Methämoglobinbildungsvermögen besitzen, der Nachweis des Methämoglobins im Blute bei Pneumokokkeninfektionen nur unter ganz besonderen Umständen gelingt. Als wichtigstes Kriterium für die Beurteilung dieser Eigenschaft der Pneumokokken in pathogenetischer Beziehung kommt daher in erster Linie der Nachweis des verringerten Sauerstoffbindungsvermögens des Blutfarbstoffes in Betracht.

\section{Zusammenfassung.}

Die Eigenschaft der Pneumokokken und des Streptococcus mucosus, auf der Blutagarplatte einen grünen Hof um die Kolonien zu bilden und die durch Blutzusatz rot gefärbte Bouillonkultur bzw. Aufschwemmung der genannten Mikroorganismen graubraun oder rotbraun zu verfärben, beruht auf der Umwandlung des Hämoglobins in Methämoglobin (Rieke, Grüter u. a.). Spektroskopisch entspricht dieser Umwandlung das. Auftreten eines deutlichen Absorptionsstreifens in Rot $(\lambda=630)$ und zweier Streifen zwischen $D$ und $E$, von denen der eine knapp bei $D(\lambda=\mathbf{5 8 0 - 5 8 i})$ und der andere näher an $E$ liegt; selten ist noch ein vierter Streifen in Blau bei $F^{\prime}(\lambda=500)$ wahrzunchmen.

Diese Methämoglobinbildung ist von der Zahl der Keime, von der Art und dem Alter der Kultur, von der Temperatur, der Anwesenheit von Sauerstoff usw. abhängig. Je größer die Keimzahl und je höher die Temperatur (Optimum bei etwa $37^{\circ} \mathrm{C}$ ), um so rascher erfolgt die Methämoglobinbildung. Sie resultiert aus der Summation der Wirkung der lebenden Keime und ihrer freien Produkte und tritt rascher ein bei Anwendung einer Bouillonkultur als bei einer frischen Aufschwemmung vom festen Nährboden. Diese Differenz wird besonders deutlich, wenn als Zusatz nicht eine Hämoglobinlösung, sondern eine Blutkörperchenaufschwemmung genommen wird. Dies hängt damit zusammen, daß in der flüssigen Kultur das wirksame Produkt sich auch außerhalb 
der Bakterienleiber befindet - was die Voraussetzung für die Methämoglobinbildung in unversehrten Erythrocyten ist -, während es bei der frischen Aufschwemmung erst in die Suspensionsflüssigkeit übergehen muß. Auch muß das methämoglobinbildende Agens die Erythrocytenmembran durchdringen können, worauf Differenzen zwisehen verschiedenen Blutarten zurückzuführen sind (verschiedene Permeabilität).

Bei gewaschenen und in Kochsalzlösung aufgeschwemmten Pneumokokken erfolgt eine Abschwächung des Methämoglobinbildungsvermögens evtl. bis zum vollkommenen Verlust desselben; letzteres ist jedoch restituierbar durch Anregung des Bakterienstoffwechsels (Zusatz von Dextrose usw.) (Cole).

Für die Annahme eines freien, methämoglobinbildenden Produktes spricht außer dem verschiedenen Verhalten der Bouillonkultur und der frischen Aufschwemmung auch das differente Verhalten gegen Desinfektionsmittel und gegen Hitze. Optochin und glykocholsaures Natrium vermögen auch in starken Konzentrationen nicht das Methämoglobinbildungsvermögen der Bouillonkulturen wesentlich zu beeinträchtigen. Halbstündiges Erhitzen im Wasserbade bei $55^{\circ} \mathrm{C}$ bewirkt eine Abschwächung dieser Eigenschaft, bei 80 und mehr Graden verursacht es bei einer frischen Aufschwemmung vom festen Nährboden vollkommenen Verlust der Eigenschaft, Methämoglobin zu bilden, während Bouillonkulturen bei Anwendung solcher Temperaturen nur eine, wenn auch starke Abschwächung dieser Eigenschaft erleiden.

Als wichtigster Beleg für die Annahme freier Produkte wird die Filtrierbarkeit derselben angeführt: es gelang durch keimfreie Filtration von Bouillonkulturen ein noch wirkendes Filtrat zu erhalten. Die relativ geringe Wirksamkeit des Filtrates wird auf die Adsorption durch die Filterporen zurückgeführt, wofür die leichte Adsorbierbarkeit durch Tierkohle und Erythrocyten spricht.

Es konnten Anhaltspunkte für die Annahme einer antagonistischen Beeinflussung der Pneumokokkenhämolyse durch das methämoglobinbildende Produkt gewonnen werden. Außer den Beobachtungen während des Wachstums auf der Blutplatte spricht dafür auch das verschiedene Verhalten der nicht erhitzten und der erhitzten, frischen Aufschwemmung von Pneumokokken bei der Prüfung ihrer antihämolytischen Fähigkeiten: die erhitzte Aufschwemmung, die das Methämoglobinbildungsvermögen verloren hat, hemmt die Immunhämolyse viel weniger als die nicht erhitzte.

Die Anwesenheit von Sauerstoff ist für die Methämoglobinbildung durch Pneumokokken von großer Bedeutung, wie aus Versuchen zu schließen ist, bei denen die Berührung mit dem Sauerstoff der Luft in verschiedener Weise variiert wurde. Auf diese Tatsache ist es hauptsächlich zurückzuführen, daß der Methämoglobinnachweis im Blute der 
mit Pneumokokken infizierten Tiere fast unmöglich ist. Die Schwierigkeit des Nachweises wird noch dadurch erhöht, daß unter den im Organismus gegebenen Verbältnissen nur unter ganz besonderen Umständen so viel Methämoglobin gebildet wird, daß dessen Nachweis gelingt, und daß die alkalische Reaktion des Blutes die Wahrnehmung stört.

Es wird durch Versuche gezeigt, daß das Methämoglobinbildungs. vermögen der Pneumokokken durch die alkalische Reaktion und die reduktionsfördernden Eigenschaften des Blutserums stark behindert wird und $\mathrm{da} B$ bereits gebildetes Methämoglobin in Hämoglobin rückverwandelt werden kann. In gleicher Art reduzierend wirken die Organzellen, besonders die der Leber.

Im Blute der mit Pneumokokken infizierten Tiere konnte eine Verringerung des Sauerstoffbindungsvermögens des Hämoglobins festgestellt werden, woraus auf die Bedeutung der methämoglobinbildenden Eigenschaft der Pneumokokken in pathogenetischer Beziehung geschlossen wird (Butterfield und Peabody).

\section{Literaturverzeichnis.}

Boxer, Zentralbl. f. Bakteriol., Parasitenk. u. Infektionskrankh., Abt. I, Orig. 40. 1906. - Butterfield und Peabody, Journ. of exp. med. 1\%. 1913. - Cole, Ebenda 20. 1914. - Dittrich, Arch. f. exp. Pathol. u. Pharmokol. 29. 1891. - Erben, Dittrichs Handb. d. Sachverständigentätigkcit. - Fili po w ski, Arch. d. scienc. d. biol. St. Petersburg 1895. - Gilbert et Fournier, Cpt. rend. des séances de la soc. de biol. i 896. - Griu ter, Zentralbl. f. Bakteriol., Parasitenk. u. Infektionskrankh, Abt. I, Orig. 50. 1909. - Ha yem, Cpt. rend. hebdom. des séances de l'acad. des sciences 102. - He ubner, Arch. f. exp. Pathol. u. Pharmakol. \%o. 1913. - Hop pe-Seyler, Med.-klin. Untersuchungen. - Jacobs thal, Berichte der 8. Tagung der Freien. Vereinigung für Mikrabiologie. Zentralbl. f. Bakteriol, Parasitenk. u. Infektionskrankh., Abt. I, Orig. 1920. - Kobert, Lehrbuch der Toxikologie. 1906. - Kobert, Pflügers Arch. f. d. ges. Physiol. 82. 1900. - Kucz ynski und Wolff, Berl. klin. Wochenschr. 1920, Nr. 33 und 34. - Kuczynski und Wolff, Zeitschr f. Hyg. u. Infektionskrankh. 92. 1921. Küster, Zeitschr. f. allg. Physiol. 66. 1910. - Masing und Siebeck, Dtsch. Arch. f. klin. Med. 99. 1910. - Oppenheimer, Handb. d. Biochemie Bd. I und IV. - Peabody, Journ. of exp. med. 18. 1913. - Rieke, Zentralbl. f. Bakteriol., Parasitenk. u. Infektionskrankh., Abt. I, Orig. 36. 1904. - Ry mowicz, Zentralbl. f. Bakteriol., Parasitenk. u. Infektionskrankh., Abt. I, Orig. 32. - Schnabel, Biochem. Zeitschr. 108. 1920. - Schnabel, Zeitschr. f. Immunitätsforsch. u. exp. Therap. 1921. - Schottmüller, Münch. med. Wochenschr. 1903, Nr. 20 und 21. - Taka ya ma, Beitr. z. Toxikol. u. d. gerichtl. Med. Verlag Enke 1905. - Weichselbaum, Kolle-Wassermanns Handb. d. pathog. Mikr.-Organe Bd. 3. - Zangen meis ter. Dtsch. med. Wochenschr. 1909, Nr. 10 und 11 . 